\title{
¿Cuándo sospechar una parálisis periódica? A propósito de un caso
}

\author{
Sara Gómez Rodríguez, Naiara Modroño Móstoles, Isabel Pavón de Paz, Clara Eduardina \\ Torán Ranero y Carmen Pérez Blanco
}

Servicio de Endocrinología. Hospital Universitario de Getafe. Getafe. Madrid (España).

\section{Correspondencia:}

Sara Gómez Rodríguez.

Hospital Universitario de

Getafe. Ctra. de Toledo, Km. 12,500. C.P. 28905. Getafe (Madrid). España.

Correo electrónico: patsara8@hotmail.com.

Recibido el 17 de abril de 2015.

Aceptado para su publicación el 7 de mayo de 2015.

\section{RESUMEN}

La parálisis periódica es una patología excepcional que afecta a los canales iónicos musculares por diferentes causas. Produce una pérdida de fuerza muscular de manera llamativa y brusca, más evidente en la zona proximal de miembros inferiores. El hallazgo de hipopotasemia coincidiendo con estos ataques nos orienta al diagnóstico y nos muestra su diana terapéutica inicial.

PALABRAS CLAVE: Parálisis Periódica. Tirotoxicosis. Hipopotasemia.

\begin{abstract}
When to suspect periodic paralysis: report of clinical case.

Periodic paralysis (PP) is an unusual disease related to a defect in muscle ion channels and caused by different pathologies. It is characterized by abrupt muscle weakness affecting rather proximal than distal muscles in lower limbs. The finding of hypokalemia during these attacks leads us to a diagnosis of hypokalemic PP and shows its initial therapeutic target.
\end{abstract}

KEY WORDS: Paralysis, Periodic. Thyrotoxicosis. Hypokalemia.

\section{INTRODUCCIÓN}

La parálisis periódica (PP) es una patología poco usual. Sus causas pueden clasificarse en hereditarias y adquiridas. Entre las primeras nos encontramos las relacionadas con alteraciones en los niveles de $\mathrm{K}^{+}$(tanto hiper como hipopotasemia) o el infrecuente síndrome de Andersen. Las segundas en su mayor porcentaje aparecen en el contexto de hipertiroidismo, como en nuestro caso. Mostramos a continuación un caso de PP asociada a debut de enfermedad de Graves-Basedow.

\section{CASO CLÍNICO}

Se trata de un paciente varón de 46 años sin antecedentes de interés, que acude a consulta por presentar pérdida de fuerza brusca en los miembros inferiores. Este cuadro se presenta de manera reiterada y episódica, autolimitándose en unas horas. Generalmente afecta a los miembros inferiores, aunque lo puede hacer de manera generalizada. Refiere episodios previos que han ido aumentando en frecuencia e intensidad en el último año. Durante el interrogatorio dirigido refiere pérdida ponderal de 20 kilos en los últimos cuatro meses sin disminución de la ingesta, temblor ocasional, irritabilidad y nerviosismo.

En la exploración física no se detectó disminución de fuerza en los miembros ni alteraciones en los reflejos osteotendinosos. Presentaba una marcha estable no patológica, sin dismetrías. Según refería, había recuperado progre- 
sivamente la fuerza muscular hacía unos minutos. Se descubrió un temblor fino distal, sin exoftalmos. La frecuencia cardiaca era de 120 latidos por minuto, presentando a la palpación un tiroides de tamaño aumentado sin palparse nódulos. Se realizó una analítica de urgencia en la que se detectó: creatinina $0,59 \mathrm{mg} / \mathrm{dl}$ (normal 0,60-1,35), sodio $142 \mathrm{mEq} / \mathrm{L}$ (135-145), potasio 2,07 $\mathrm{mEq} / \mathrm{l}(3,5-5)$, magnesio $1,64 \mathrm{mg} / \mathrm{dl}(1,7-2,5)$, calcio $8,01 \mathrm{mg} / \mathrm{dl}(8,50-10,50)$, calcio iónico $3,95 \mathrm{mg} / \mathrm{dl}(4,1-5,3)$, proteínas totales $6,47 \mathrm{mg} / \mathrm{dl}(6,00-8,50)$. Un cuadro de pérdida de fuerza coincidiendo con hipopotasemia nos orientó hacia el diagnóstico de parálisis periódica. Dada la presencia de semiología característica de patología tiroidea, se solicitó un estudio hormonal, hallándose un hipertiroidismo primario de origen autoinmune con los siguientes parámetros: T4L 4,07 ng/ dl $(0,9-1,7), \mathrm{TSH}<0,008 \mathrm{mUl} / \mathrm{l}(0,4-4,8)$, T3L 15,58 $\mathrm{pg} / \mathrm{ml}(2,3-4,2)$, anticuerpos antitiroglobulina 62,7 $\mathrm{UI} / \mathrm{ml}$ (0-60), anticuerpos antiperoxidasa $1269 \mathrm{UI}$ $\mathrm{ml}(0-60)$, TSI 5,7 UI/I (0-1,75). La vitamina D y PTH fueron normales $(28 \mathrm{ng} / \mathrm{ml}$ [20-55] y $26 \mathrm{pg} / \mathrm{ml}$ [1180], respectivamente). La primera prueba complementaria que debemos solicitar ante un hipertiroidismo es una gammagrafía tiroidea, que en nuestro caso mostraba una hipercaptación difusa. Todos estos datos nos orientaban a una enfermedad de Graves como causante del cuadro. En el momento agudo se inicia tratamiento con $40 \mathrm{mEq}$ de potasio intravenoso consiguiendo la normalización de las cifras $(4,1 \mathrm{mEq} / \mathrm{l})$, y de forma domiciliaria se propone propranolol $10 \mathrm{mg}$ y metimazol $30 \mathrm{mg}$ diarios con disminución de dosis progresiva. En el momento actual mantiene tratamiento con metimazol $5 \mathrm{mg}$ al día con remisión parcial de los síntomas y función tiroidea normal, sin haber presentado nuevos episodios de parálisis.

\section{DISCUSIÓN}

La PP presenta una incidencia de 1 por cada 100.000 personas $^{1}$, y la causa más frecuente es la asociada a hipopotasemia. La fisiopatología está en relación con los canales iónicos musculares. Una alteración en los genes que codifican la subunidad $\alpha-1$ de la dihidropiridina de los canales de $\mathrm{Ca}^{++}$del músculo esquelético produce el $70 \%$ de las PP hereditarias. Kim et al. demuestran que los pacientes con PP presentan un aumento de $\mathrm{Ca}^{++}$ intracelular, lo que produce una apertura de los canales de $\mathrm{K}^{+}$dependientes de $\mathrm{Ca}^{++}$, reduciéndose el $\mathrm{K}^{+}$extracelular ${ }^{2}$. En otros casos, una mutación en el gen SCN4A del canal de $\mathrm{Na}^{+}$es el origen de este cuadro, produciendo una despolarización anómala. Además, se han visto implicaciones de la bomba $\mathrm{N}^{+} / \mathrm{K}^{+}$ATP-asa del sarcolema. Este puede ser el origen de la PP asociada a tirotoxicosis. La respuesta $\beta$-adrenérgica típica de los estados hipertiroideos estimula la actividad de la bomba de ATP, produciéndose un transporte de $\mathrm{K}^{+}$dentro de la célula ${ }^{3-8}$. La clínica consiste en debilidad muscular generalizada de instauración brusca con indemnidad de los músculos respiratorios y faciales, sin pérdida de consciencia. Es típica la debilidad más manifiesta en los músculos proximales y en los miembros inferiores, así como la disminución de los reflejos osteotendinosos. Estos episodios suelen comenzar en la adolescencia y presentarse de manera episódica, cursando con normalidad en los periodos intercurrentes. La duración habitual de la parálisis es de unas horas, pero puede ser de días. Son favorecidos por situaciones estresantes, ejercicio intenso, $\beta 2$-adrenérgicos o una comida rica en hidratos de carbono que produce un aumento del transporte de $\mathrm{K}^{+}$al interior de la célula debido a la acción de insulina. En nuestro caso, el paciente reconoció la ingesta de seis bebidas carbonatadas de alto contenido calórico el día previo al último episodio. Para establecer el diagnóstico debemos realizar una correcta anamnesis sobre episodios previos, antecedentes familiares y posibles desencadenantes. En las pruebas complementarias solicitaremos iones en plasma y pruebas de función tiroidea para descartar una causa adquirida, ya que en la tirotoxicosis nos encontraremos también un $\mathrm{K}^{+}$bajo. Deberemos realizar un electrocardiograma para descartar el síndrome de Andersen, dado que se caracteriza por presentar un QT largo. En caso de sospecha existen tests de provocación, como la administración de glucosa oral $(2 \mathrm{mg} / \mathrm{kg}$ peso), insulina subcutánea $(10 \mathrm{UI})^{9}$, así como la realización de ejercicio (30 minutos de carrera). La confirmación de una alteración genética nos dará el diagnóstico definitivo en los casos dudosos de causa hereditaria. Existe una entidad que cursa de manera similar en el contexto de una enfermedad sistémica, pero en este caso nos encontraremos un paciente con evidencias clínicas o analíticas de pérdidas gastrointestinales o renales y persistencia de hipopotasemia tras los ataques.

Para el tratamiento agudo se pueden administrar $30 \mathrm{mEq}$ de $\mathrm{K}^{+}$cada 30 minutos hasta la normalización iónica, con especial cuidado en no producir hiperpotasemia de rebote, presente en el $40 \%$ de los $\operatorname{casos}^{10}$. Más importante es la prevención de estos episodios. Deberemos recomendar una dieta baja en hidratos de carbono y evitar ejercicio intenso. De igual manera, se pueden iniciar los inhibidores de anhidrasa carbónica (diclofenamida 
50mg dos veces al día) ${ }^{11}$. En nuestro paciente, al tratarse de tirotoxicosis, iniciamos tratamiento antitiroideo y asociamos $\beta$-bloqueantes, que además de disminuir los síntomas, bloquean la bomba de $\mathrm{Na}^{+} / \mathrm{K}^{+}$ATP-asa.

Con este caso se muestra que, dentro del diagnós- tico diferencial de la pérdida de fuerza muscular (tabla 1), la parálisis periódica tiene su cabida, sobre todo cuando se presenta en forma de ataques. Conociendo su fisiopatología podemos tratar de manera específica y prevenir su aparición, tan solo con recomendaciones sobre el estilo de vida.

\begin{tabular}{|c|c|c|c|c|c|c|}
\hline & $\begin{array}{c}\text { PP } \\
\text { hipopotasemia }\end{array}$ & $\begin{array}{c}\text { PP } \\
\text { hipertiroidismo }\end{array}$ & $\begin{array}{c}\text { Sd. } \\
\text { de Andersen }\end{array}$ & $\begin{array}{l}\text { Miastenia } \\
\text { gravis }\end{array}$ & $\begin{array}{l}\text { Miopatías } \\
\text { metabólicas }\end{array}$ & $\begin{array}{l}\text { Hipopotasemia } \\
\text { secundaria }\end{array}$ \\
\hline Frecuencia & Infrecuente & Infrecuente & Mensual & $\begin{array}{l}\text { Semanal en } \\
\text { fases precoces } \\
\text { con aumento } \\
\text { progresivo }\end{array}$ & Variable & Variable \\
\hline Duración & Horas-Días & Horas-Días & Días & $\begin{array}{l}\text { Menor en fases } \\
\text { precoces }\end{array}$ & Variable & $\begin{array}{l}\text { Depende de la } \\
\text { enfermedad de } \\
\text { base }\end{array}$ \\
\hline Precipitantes & $\begin{array}{l}\text { Ejercicio. Hidra- } \\
\text { tos de carbono. } \\
\text { Estrés. } \beta \text {-adre- } \\
\text { nérgicos }\end{array}$ & $\begin{array}{l}\text { Ejercicio. Hidra- } \\
\text { tos de carbono. } \\
\text { Estrés. B-adre- } \\
\text { nérgicos }\end{array}$ & $\begin{array}{l}\text { Descanso tras } \\
\text { ejercicio }\end{array}$ & Esfuerzo físico & $\begin{array}{l}\text { Esfuerzo } \\
\text { físico }\end{array}$ & \\
\hline Etiología & $\begin{array}{l}\text { Alteración en } \\
\text { canales iónicos } \\
\text { musculares por } \\
\text { defecto genético }\end{array}$ & Tirotoxicosis & $\begin{array}{l}\text { Alteración en } \\
\text { canales iónicos } \\
\text { musculares por } \\
\text { defecto genético }\end{array}$ & $\begin{array}{l}\text { Alteración en } \\
\text { transmisión } \\
\text { neuromuscular } \\
\text { por enfermedad } \\
\text { autoinmune }\end{array}$ & $\begin{array}{l}\text { Miopatía } \\
\text { mitocondrial. } \\
\text { Alteración en } \\
\text { el metabolis- } \\
\text { mo lipídico o } \\
\text { del glucógeno }\end{array}$ & $\begin{array}{l}\text { Enfermedad renal } \\
\text { o sistémica }\end{array}$ \\
\hline Asociaciones & $\begin{array}{l}\text { Miopatía de co- } \\
\text { mienzo tardío }\end{array}$ & $\begin{array}{l}\text { Alteraciones } \\
\text { hormonales. } \\
\text { Síntomas de } \\
\text { hipertiroidismo }\end{array}$ & $\begin{array}{l}\text { QT largo. Arrit- } \\
\text { mias ventricu- } \\
\text { lares }\end{array}$ & $\begin{array}{l}\text { Afectación } \\
\text { muscular, ocular } \\
\text { y respiratoria }\end{array}$ & $\begin{array}{l}\text { Mialgias. } \\
\text { Mioglobinuria. } \\
\text { No ataques }\end{array}$ & $\begin{array}{l}\text { No revierte tras } \\
\text { corrección }\end{array}$ \\
\hline Potasio & Bajo & Bajo & Indiferente & Indiferente & Indiferente & Bajo \\
\hline Tratamiento & $\begin{array}{l}\text { Inhibidores de } \\
\text { anhidrasa car- } \\
\text { bónica }\end{array}$ & $\begin{array}{l}\text { Antitiroideos. } \\
\beta \text {-bloqueantes }\end{array}$ & $\begin{array}{l}\text { Inhibidores de } \\
\text { anhidrasa car- } \\
\text { bónica }\end{array}$ & $\begin{array}{l}\text { Anticolinérgicos. } \\
\text { Inmunosupreso- } \\
\text { res. Plasmafére- } \\
\text { sis. Timectomía }\end{array}$ & $\begin{array}{l}\text { Dieta. Dismi- } \\
\text { nuir ejercicio. } \\
\text { Suplementa- } \\
\text { ción vitamí- } \\
\text { nica }\end{array}$ & Patología de base \\
\hline
\end{tabular}

Tabla 1. Diagnóstico diferencial de la pérdida de fuerza muscular. PP: Parálisis periódica 


\section{BIBLIOGRAFÍA}

1. Fontaine B. Periodic paralysis. Adv Genet. 2008; 63: 3-23.

2. Kim JB, Kim SJ, Kang SY, Yi JW, Kim SM. The large-conductance calcium-activated potassium channel holds the key to the conundrum of familial hypokalemic periodic paralysis. Korean J Pediatr. 2014; 57 (10): 445-50.

3. Ptácek LJ, Tawil R, Griggs RC, Engel AG, Layzer RB, Kwieciński $\mathrm{H}$ et al. Dihydropyridine receptor mutations cause hypokalemic periodic paralysis. Cell. 1994; 77 (6): 863-8.

4. Wang Q, Liu M, Xu C, Tang Z, Liao Y, Du R et al. Novel CACNA1S mutation causes autosomal dominant hypokalemic periodic paralysis in a Chinese family. $\mathrm{J}$ Mol Med (Berl). 2005; 83 (3): 203-8.

5. Matthews E, Labrum R, Sweeney MG, Sud R, Haworth A, Chinnery PF et al. Voltage sensor charge loss accounts for most cases of hypokalemic periodic paralysis. Neurology. 2009; 72 (18): 1544-7.

6. Corrochano S, Männikkö R, Joyce PI, McGoldrick P,
Wettstein J, Lassi G et al. Novel mutations in human and mouse SCN4A implicate AMPK in myotonia and periodic paralysis. Brain. 2014; 137 (12): 3171-85.

7. Ober KP. Thyrotoxic periodic paralysis in the United States Report of 7 cases and review of the literature. Medicine (Baltimore). 1992; 71 (3): 109-20.

8. Lin YF, Wu CC, Pei D, Chu SJ, Lin SH. Diagnosing thyrotoxic periodic paralysis in the ED. Am J Emerg Med. 2003; 21 (4): 339-42.

9. Cannon SC, George AL. Pathophysiology of myotonia and periodic paralysis. In: Asbury AK, McKhann GM, McDonald WI, Goadsby PJ, McArthur JC, editors. Diseases of the nervous system. 3rd edition. Cambridge: Cambridge University Press; 2002. p.1183.

10. Manoukian MA, Foote JA, Crapo LM. Clinical and metabolic features of thyrotoxic periodic paralysis in 24 episodes. Arch Intern Med. 1999; 159 (6): 601-6.

11. Tawil R, McDermott MP, Brown R Jr, Shapiro BC, Ptacek LJ, McManis PG et al. Randomized trials of dichlorphenamide in the periodic paralyses. Working Group on Periodic Paralysis. Ann Neurol. 2000; 47 (1): 46-53. 